Physical Therapy Journal of Indonesia (PTJI) 2021, Volume 2, Number 2: 61-66

E-ISSN : 2722-6034; P-ISSN : 2722-0125

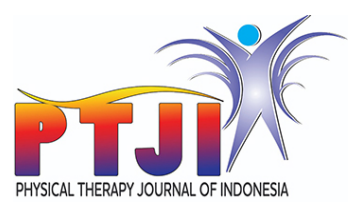

\title{
The Effectiveness of Core Stability Exercise to Improve Functional Ability in A Lumbar Herniated Nucleus Pulposus Patient: A Case Study
}

\author{
Aditya Denny Pratama ${ }^{1 *}$, Muhamad Elfitra Salam ${ }^{1}$
}

\begin{abstract}
Background: Hernia Nucleus Pulposus (HNP) is a condition in which the nucleus pulposus has bulged from the intervertebral disc, consequently damages the walls of the annulus fibrosus and compresses the nerves. Clinical problems such as radiating pain, sensory disturbances according to dermatomes, muscle weakness, restricted range of motion, especially during flexion, and decreased functional ability. Core stability exercise is one of the physiotherapy treatments to reduce pain and improve the patient's functional ability with lumbar HNP. The purpose of this study is to determine the effectiveness of core stability exercise on increasing functional ability in cases of lumbar HNP with Modified Oswestry Low Back Pain Disability Questionnaire as a parameter.
\end{abstract}

Methods: A single case study provided a physiotherapy intervention to a 56-year-old female patient for four weeks with

four evaluations. The dose of exercise given was three times a week, three sets, five repetitions, 6-9 minutes of each type of exercise, and hold time $5-10$ seconds. The improvement of functional ability is measured by using the Modified Oswestry Low Back Pain Disability Questionnaire.

Results: There was an improvement in functional ability as measured by Modified Oswestry Low Back Pain Disability Questionnaire. At pre-intervention, the Modified Oswestry score was $52 \%$ meaning the patient had severe disability. On the 4th week evaluation, the patient's Modified Oswestry score decreased to $26 \%$, indicating moderate disability.

Conclusion: This study showed that core stability exercise effectively improved functional ability in a patient with lumbar HNP.
1Physiotherapy Department, Vocational Education Program, Universitas Indonesia, Jl. Akses Vokasi UI, Kukusan, Kecamatan Beji, Kota Depok, Jawa Barat, 16424
*Corresponding to: Aditya Denny Pratama, Physiotherapy Department, Vocational Education Program, Universitas Indonesia; Email: pratama.aditya@ui.ac.id
Received : 2021-06-29 Accepted : 2021-09-26 Published: 2021-12-02

Keywords: core stability exercise, lumbar herniated nucleus pulposus, Modified Oswestry Low Back Pain Disability Questionnaire Cite this Article: Pratama, A.D., Salam, M.E. 2021. The Effectiveness of Core Stability Exercise to Improve Functional Ability in A Lumbar Herniated Nucleus Pulposus Patient: A Case Study. Physical Therapy Journal of Indonesia 2(2): 61-66. D0I: 10.51559/ptji.v2i2.24

\section{INTRODUCTION}

The burden of non-infectious diseases is increasing, although the infectious diseases infectious diseases have not been fully resolved. Based on the National and Subnational Disease Burden Analysis 2017, several degenerative diseases have an increase of between $15-25 \%$, one of which is Low Back Pain or LBP in Indonesia. ${ }^{1}$ One of the most common causes is Herniated Nucleus Pulposus (HNP).

HNP is a condition where the nucleus pulposus bulges from the intervertebral disc, damaging the annulus fibrosus wall and compressing the nerves. ${ }^{2}$ The incidence rate of HNP globally is 5 to 20 cases per 1000 adults per year. ${ }^{3}$ A study presented 4456 people (25\% of the total visits) suffered from pain, and 819 people $(18.37 \%)$ of them were pain due to HNP in the 14 teaching hospitals in May 2002. ${ }^{4}$ HNP most often occurs in the third to fifth decades of life and most frequent (90\%) occurred in the L4-L5, L5-S1 segments. ${ }^{3,5}$ Clinical symptoms are radiating pain, sensory disturbances, muscle weakness, restricted range of motion, and some activities that provoke radiating pain, such as coughing and sneezing. ${ }^{2}$

Core stability exercise is a physiotherapy intervention with isometric contractions to increase muscle strength and central/trunk stability by activating stabilising muscles. ${ }^{6}$ The evaluation parameter used is the Modified Oswestry Low Back Pain Disability Questionnaire (MOLBPDQ). MOLBPDQ consists of 10 domains with five answer choices describing the patient's disability. Each answer has a different value, starting with a score of 0 , which means there is no disability, up to 5 for the most severe disability. ${ }^{7,8}$ MOLBPDQ has an excellent intraclass correlation coefficient. ${ }^{7}$

This case study aims to determine the effectiveness of core stability exercises on increasing functional ability in a lumbar HNP patient. While the benefits of writing from this case study are as a learning material and reference for all people who want to increase knowledge, increase understanding related to lumbar HNP and core stability exercise, and be able to apply core stability exercise at home, hospital, or clinic. 


\section{CASE STUDY}

Before the intervention, the patient was given informed consent as subject to this case study, agreed to report her data, and received physiotherapy intervention to improve her impairments.

A 56-year-old woman diagnosed with LBP + HNP complained of radiating pain from the lower back to the left heel and stiffness in both legs. In

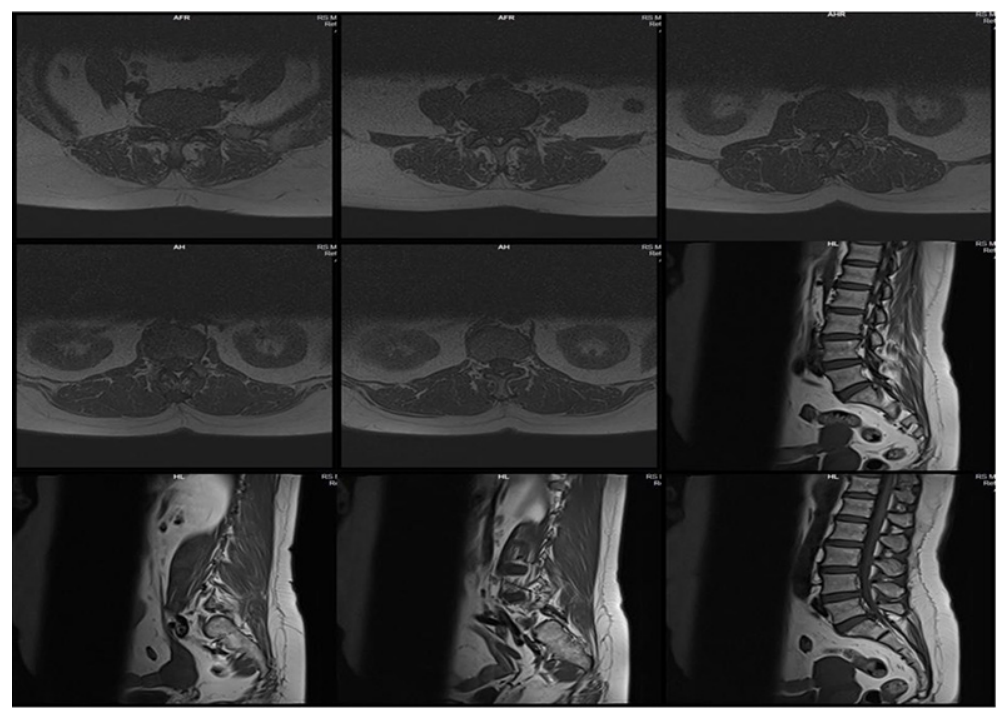

Figure 1. Magnetic resonance imaging (MRI) of the patient

Table 1. Range of Motion Examination Result

\begin{tabular}{|c|c|c|c|c|c|c|}
\hline \multirow{2}{*}{ Joint } & \multirow{2}{*}{ Movement } & \multirow{2}{*}{$\begin{array}{c}\text { Normal } \\
\text { ROM }\end{array}$} & \multicolumn{2}{|c|}{ Active ROM } & \multicolumn{2}{|c|}{ Passive ROM } \\
\hline & & & Right & Left & Right & Left \\
\hline \multirow{3}{*}{ Trunk } & $S$ & $30^{\circ}-0^{\circ}-90^{\circ}$ & \multicolumn{2}{|c|}{$25^{\circ}-0^{\circ}-60^{\circ}$} & \multicolumn{2}{|c|}{$30^{\circ}-0^{\circ}-80^{\circ}$} \\
\hline & $\mathrm{F}$ & $30^{\circ}-0^{\circ}-30^{\circ}$ & \multicolumn{2}{|c|}{$10^{\circ}-0^{\circ}-20^{\circ}$} & \multicolumn{2}{|c|}{$20^{\circ}-0^{\circ}-25^{\circ}$} \\
\hline & $\mathrm{T}$ & $60^{\circ}-0^{\circ}-60^{\circ}$ & \multicolumn{2}{|c|}{$40^{\circ}-0^{\circ}-45^{\circ}$} & \multicolumn{2}{|c|}{$60^{\circ}-0^{\circ}-60^{\circ}$} \\
\hline \multirow{3}{*}{ Hip } & S & $15^{\circ}-0^{\circ}-120^{\circ}$ & $15^{\circ}-0^{\circ}-80^{\circ}$ & $15^{\circ}-0^{\circ}-75^{\circ}$ & $15^{\circ}-0^{\circ}-85^{\circ}$ & $15^{\circ}-0^{\circ}-85^{\circ}$ \\
\hline & $\mathrm{F}$ & $45^{\circ}-0^{\circ}-30^{\circ}$ & $45^{\circ}-0^{\circ}-30^{\circ}$ & $45^{\circ}-0^{\circ}-30^{\circ}$ & $45^{\circ}-0^{\circ}-30^{\circ}$ & $45^{\circ}-0^{\circ}-30^{\circ}$ \\
\hline & $\mathrm{T}$ & $35^{\circ}-0^{\circ}-45^{\circ}$ & $35^{\circ}-0^{\circ}-45^{\circ}$ & $35^{\circ}-0^{\circ}-45^{\circ}$ & $35^{\circ}-0^{\circ}-45^{\circ}$ & $35^{\circ}-0^{\circ}-45^{\circ}$ \\
\hline
\end{tabular}

F, frontal plane; $\mathrm{S}$, sagittal plane; $\mathrm{T}$, transverse plane.

Table 2. Muscle Strength and Pain Scale Examination Result

\begin{tabular}{|c|c|c|c|c|c|}
\hline \multirow{2}{*}{ Joint } & \multirow{2}{*}{ Muscle Group } & \multicolumn{2}{|c|}{ MMT } & \multicolumn{2}{|c|}{ VAS } \\
\hline & & Right & Left & Right & Left \\
\hline \multirow[t]{4}{*}{ Trunk } & Fleksor & \multicolumn{2}{|c|}{3} & \multicolumn{2}{|c|}{4} \\
\hline & Ekstensor & \multicolumn{2}{|c|}{4} & \multicolumn{2}{|c|}{3} \\
\hline & Lateral fleksor & 5 & 4 & 0 & 3 \\
\hline & Rotator & 4 & 4 & 0 & 3 \\
\hline \multirow{2}{*}{ Myotome } & \multirow{2}{*}{ Movement } & \multicolumn{2}{|c|}{ MMT } & \multicolumn{2}{|c|}{ VAS } \\
\hline & & Right & Left & Right & Left \\
\hline L2 & Hip flexion & 4 & 4 & 2 & 3 \\
\hline L3 & Knee extension & 5 & 5 & 0 & 0 \\
\hline L4 & Ankle dorsal flexion & 5 & 5 & 0 & 0 \\
\hline L5 & Great toe extension & 5 & 5 & 0 & 0 \\
\hline S1 & Ankle plantar flexion & 5 & 5 & 0 & 0 \\
\hline
\end{tabular}

July 2019 , the patient felt a painful sensation in both legs. In December 2020, the patient complained of radiating pain to the left heel, especially when walking and bending over, making it difficult to pray. On December 26th, 2020, the patient went to a general practitioner and conducted laboratory examinations to determine uric acid, cholesterol, blood sugar levels. The results were normal. On January 13rd, 2021, the patient went to the orthopaedic then advised her to take an X-ray. On January 14th, 2021, X-ray results came out with the conclusion of Lumbar Spondylosis with Osteoporosis. On January 27th, 2021, the patient took MRI, and the result was low back pain with hernia nucleus pulposus (Figure 1). On January 28th, 2021, the patient came to physiotherapy for the first time. Until March 21st, 2021, the patient had undergone ten sessions of physiotherapy. The patient's current condition is radiating pain in the lower back to the left heel and stiffness in both legs when bending over; the patient cannot walk far for a maximum of 10 minutes and sitting for 30 minutes. The patient also had difficulty performing household activities such as sweeping, mopping, washing clothes, and cooking.

\section{EXAMINATION AND CLINICAL PROBLEM}

The patient underwent several examinations to determine the diagnosis, including the range of motion (ROM), muscle strength, pain level, anthropometric, sensory, reflexes, specific tests, and the MOLBPDQ. With the following examination results:

1. ROM

ROM is the amount of movement that occurs in a joint. The active and passive ROMs were measured with a goniometer in several positions, such as supine lying, prone lying, and sitting 9 Table 1 . There were limited ROMs in trunk flexion, extension, bilateral lateral flexion, bilateral rotation.

2. Muscle strength and pain scale

The measurement of muscle strength used manual muscle testing (MMT) presents in Table 2. In the MMT examination, the physiotherapist positions patients' joints in a neutral position. The MMT scoring system starts from 1 to $5 .{ }^{10}$ Meanwhile, the visual analogue scale (VAS) was used to measure the pain level of the patient. VAS is a simple method to measure pain intensity sensitive, inexpensive, and easy to use. Physiotherapists need to educate and explain the pain about VAS on each scale, then ask the patients' pain scale. ${ }^{11}$ 
The decrease of muscle strength of flexor trunk, extensor trunk, lateral flexor trunk, bilateral rotator trunk, and bilateral L2 myotome muscles was found in the patient. The patient felt the pain during trunk flexion, extension, left lateral flexion and left rotation. Also, the pain arises during hip flexion on both legs.

3. Anthropometric examination

The anthropometric examination measured height, weight, body circumference, fat composition, and muscle atrophy. In this case, an anthropometric was performed to determine the presence of muscle atrophy in

Table 3. Anthropometric Examination Result

\begin{tabular}{cccc}
\hline Description & Right & Left & Difference \\
\hline $20 \mathrm{~cm}$ from SIAS & $54 \mathrm{~cm}$ & $54 \mathrm{~cm}$ & 0 \\
$10 \mathrm{~cm}$ from tuberosities tibia & $40 \mathrm{~cm}$ & $40 \mathrm{~cm}$ & 0 \\
\hline
\end{tabular}

Table 4. Sensory Examination Result

\begin{tabular}{cccc}
\hline Methods & Dermatome & Dextra & Sinistra \\
\hline Sharp-dull & L2 & $100 \%$ & $100 \%$ \\
& L3 & $100 \%$ & $100 \%$ \\
L4 & $100 \%$ & $100 \%$ \\
Soft touch & L5 & $100 \%$ & $100 \%$ \\
& S1 & $100 \%$ & $100 \%$ \\
& L2 & $100 \%$ & $100 \%$ \\
& L3 & $100 \%$ & $100 \%$ \\
& L4 & $100 \%$ & $100 \%$ \\
& L5 & $100 \%$ & $100 \%$ \\
& S1 & $100 \%$ & $100 \%$ \\
\hline
\end{tabular}

Table 5. Physiological Reflexes Examination Result

\begin{tabular}{lcc}
\hline Physiological reflex & Dextra & Sinistra \\
\hline Patellar tendon & +1 & +1 \\
Achilles' tendon & +2 & +2 \\
\hline
\end{tabular}

Table 6. Specific Tests Used for Lumbar HNP

\begin{tabular}{llll}
\hline No. & \multicolumn{1}{c}{ Specific test } & Hasil & \multicolumn{1}{c}{ Description } \\
\hline 1. & Straight Leg Raise (SLR) Test & Negative & $\begin{array}{l}\text { The patient felt radiating } \\
\text { pain from lower back to } \\
\text { heel } \\
\text { The patient felt radiating } \\
\text { pain from lower back to } \\
\text { heel } \\
\text { The patient felt radiating } \\
\text { pain from lower back to } \\
\text { heel }\end{array}$ \\
3. & Bragard's Test & Positive & \\
\hline
\end{tabular}

leg muscles using elastic tape marked in 1-cm increments that measured $20 \mathrm{~cm}$ below the spina iliaca anterior superior for thigh muscles and $10 \mathrm{~cm}$ below the tuberosities tibia for the calf muscles ${ }^{12}$ as presents in Table 3 . There is no muscle atrophy on both legs.

4. Sensory examination

The sensory examination was carried out to determine sensory disturbances, which are present in Table 4. Other sensory functions innervate different skin areas of the lower extremity for each spinal nerve segment, called dermatomes. This examination was performed by scratching the skin and dull stimulus and a soft touch on the dermatome area. ${ }^{13}$ There is no decrease in sensibility along the L2-S1 dermatome area.

5. Physiological reflexes

The physiological reflex examination confirms upper motor neuron or lower motor neuron disorders. This examination was performed by tapping the Patellar and Achilles' tendon with reflex hammer, ${ }^{14}$ as presents in Table 5. There was hyporeflexia in the bilateral tendon patellar reflex.

6. Specific tests

The straight Leg Raise (SLR) test is the most common passive examination in lower extremity cases. The procedure of this test, the physiotherapist, started with the patient lies in supine, hip slightly internally rotated, knee extended. Then physiotherapist slowly flexed the hip until the patient complained of radiating pain. The patient felt the pain at $70^{\circ}$ during hip flexion; but pain after $70^{\circ}$ was usually caused by joint facet. Braggad's test was carried out with ankle dorsiflexion after pain appears during SLR. Meanwhile, the physiotherapist performed the Neri test by instructing the patient to flex her neck after pain occurs during Braggard's test, $\underline{15}$ as present in Table 6 .

7. MOLBPDQ

The physiotherapist also collected the patient's ability using the MOLBPDQ. The total score of MOLBPDQ of the patient was 52\%, represents a moderate disability.

Based on these assessments, the physiotherapy goals for the patient was to improve functional ability by core stability exercise with the types of pelvic tilting exercise, bridging exercise, four-point kneeling exercise with the arm lift, four-point kneeling exercise with leg lift, and cat-camel exercise (Figure 2). The core stability exercise was given three sets three times a week for four weeks, from March 22, 2021, to April $18,2021$. 


\section{INTERVENTIONS}

Core stability exercise aims to activate the deep stability muscles that are generally inactive in patients with lumbar pathologies, such as lumbar HNP. ${ }^{16,17}$ In this study, several types of core stability were used, including pelvic tilting exercise, bridging exercise, four-point kneeling exercise with an arm lift and leg lift, and cat-camel exercise.

Pelvic tilting exercise is an exercise that use to reduce symptoms in LBP patients. Anterior pelvic tilt can increase the strength of lumbar lordosis muscles. In contrast, posterior pelvic tilt can correct the alignment of the lumbar spine in LBP patients. ${ }^{18}$ Bridging exercise is a closed kinetic chain exercise

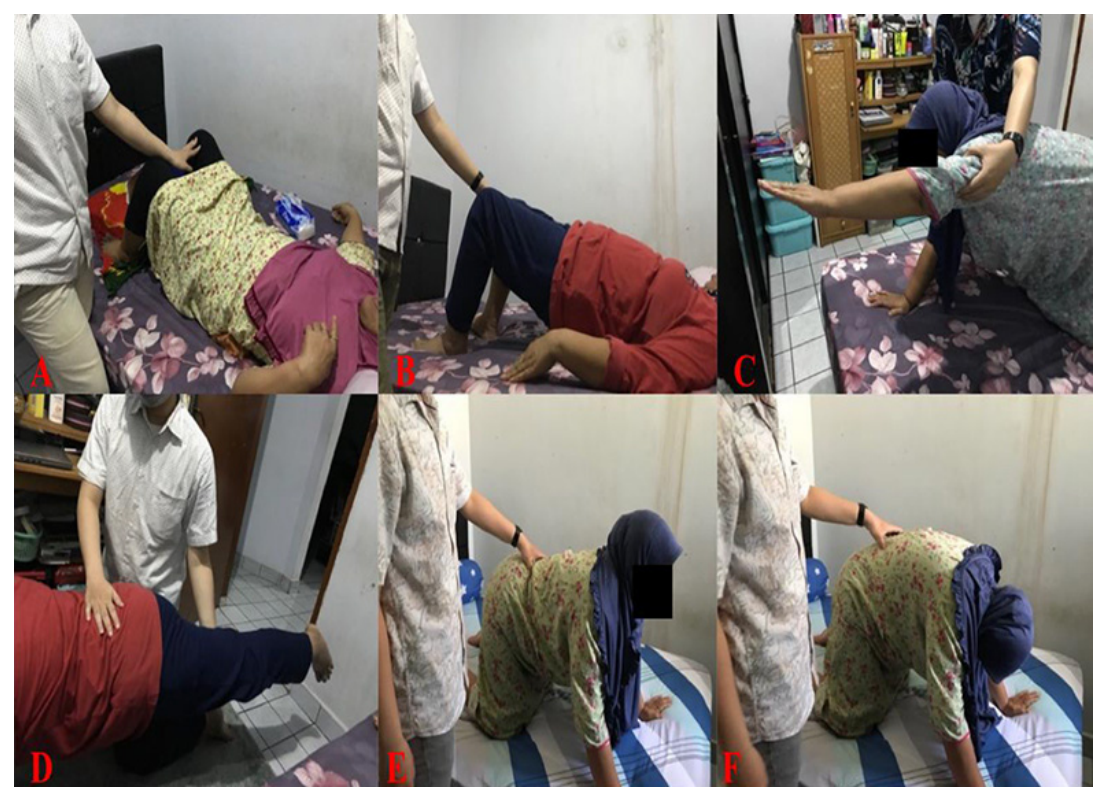

Figure 2. A. Pelvic tilting exercise; B. Bridging exercise; C. Kneeling with arm lift; D. Kneeling with leg lift; E\&F.Cat-camel exercise

Table 7. Activated Muscles During Core Stability Exercise

\begin{tabular}{ll}
\hline Type of Core Stability Exercise & \multicolumn{1}{c}{ Activated Muscles during Exercise } \\
\hline Pelvic tilting exercise & $\begin{array}{l}\text { m. erector spine, m. multifidus, m. transversus } \\
\text { abdominus, m. rectus abdominis, m. external } \\
\text { oblique, m. internal oblique. }{ }^{18}\end{array}$
\end{tabular}

Bridging exercise

$\mathrm{m}$. internal oblique, $\mathrm{m}$. rectus abdominis, $\mathrm{m}$. erector spine, m. quadratus lumborum, m.

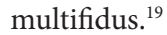

Four-point kneeling exercise

m. transversus abdominus, m. multifidus, $\mathrm{m}$. internal oblique, $\mathrm{m}$. external oblique, $\mathrm{m}$. rectus abdominus. ${ }^{20}$

Cat-camel exercise

$\mathrm{m}$. erector spine, $\mathrm{m}$. rectus abdominis, $\mathrm{m}$. internal oblique, $\mathrm{m}$. external oblique, $\mathrm{m}$. serratus anterior, and $\mathrm{m}$. triceps. ${ }^{21}$ aim to increase core muscles. Bridging exercise is easy, comfortable, and can reduce symptoms in LBP patients. ${ }^{19}$ Four-point kneeling exercise aims to improve stability and core muscle strength and reduce pain. ${ }^{20}$ Meanwhile, cat-camel exercise is a closed kinetic chain exercise that aims to increase thoracic and lumbar muscles, reduce pain, reduce intradiscal pressure, and stretch muscles around thoracic and lumbar vertebrae..$^{21}$ Table 7 describes the muscles that were activated during each type of core stability exercise.

\section{EVALUATION}

Figure 3 presents that core stability exercise affect pain intensity based on the MOLBPDQ parameter. On the examination, the pain intensity was 4 , which represented very severe pain. On the 1st week of evaluation, the pain intensity decreased to 2 means that the pain felt mild. However, on the 2nd-week evaluation, the pain increased to 3 , which showed severe pain because the patient performed more lifting activities than the last week. Thus, the patient was given a home program to minimise and modify the lifting and bending down activities. On the 3rd and 4th week evaluation, the pain intensity decreased to 2, which showed mild pain.

Figure 4 presents the effectiveness of core stability exercise in improving functional ability measured with MOLBPDQ. The MOLBPDQ score was $52 \%$ on the examination, which means the patient had a severe disability. On the 1st week of evaluation, the MOLBPDQ score decreased to $44 \%$. On the 2 nd and 3 rd evaluations, the patient had more significant improvement than the previous week with a MOLBPDQ score of $44 \%$ and $30 \%$, respectively. A better functional ability in the house working, walking, and sitting had experienced by the patient. Thus, on the 4th evaluation, the MOLBPDQ score was decreased to $26 \%$, representing a moderate disability.

\section{DISCUSSION}

\section{Mechanism of Core Stability Exercise in Reduc- ing Pain Intensity}

Core stability exercise is an exercise that activates local (trunk muscles) and global stability (trunk, upper- and lower-extremities muscles) by preventing lumbopelvic joint tension and correcting posture. There is a neutral zone in the lumbar vertebrae for the synergistic interaction between the active stability systems (including the muscles, tendons, and nerves) and passive stability systems (including the discs, ligaments, and bones) that control the movement of the intervertebral disc. In an HNP pathology, the neutral zone will be 
disrupted due to a working imbalance of the active stability system, one of which is a decrease in the capacity of stabilising the passive stability systems, which results in pain. Core stability exercises can reduce pain intensity by improving coordination and activation of stabilising muscles that reducing the load on the intervertebral discs, which enhance the quality of movement in the trunk. ${ }^{17}$

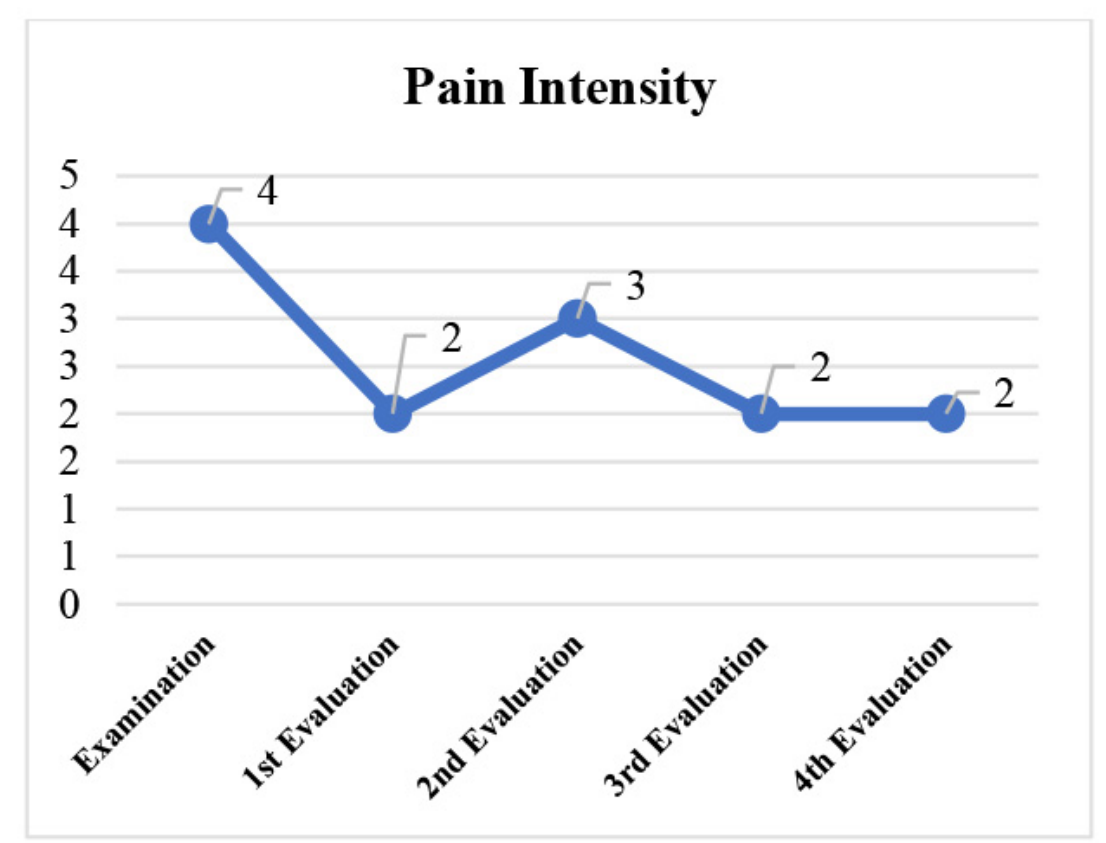

Figure 3. Pain intensity evaluation result of the patient

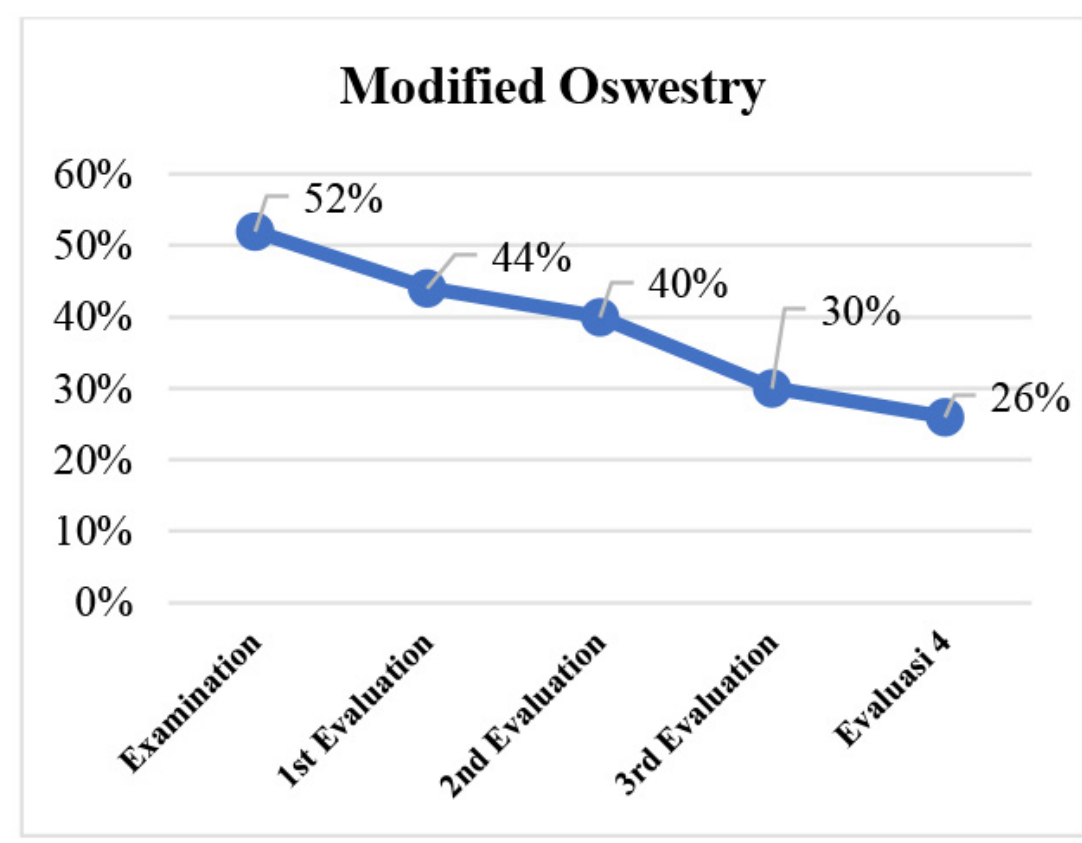

Figure 4. Functional ability evaluation result of the patient
The previous study found that the cat-camel exercise contributes to the improvement of the patient's functional abilities by activating lumbar stability muscles and reducing pain sensation that reduces the excessive movement of the intervertebral disc. ${ }^{21}$ Core stability exercise activates the lumbar stabilising muscle fibres such as multifidus, transversus abdominis, erector spine, consequently increasing neuromuscular control, muscle strength, and muscle endurance. ${ }^{16}$ In addition, the core stability exercise might stimulate the brain to release $\beta$-endorphin (BE), an endogenous opioid that causes analgesic effects. BE is a peptide released by an adrenocorticotropic hormone from the anterior lobe of the pituitary gland due to increased metabolism and body heat during exercise. BE acts on endogenous opioid receptors that modulate pain sensation at the spinal cord level. Thus, performing the core stability exercise affects circulating PB levels in the blood vessels, resulting in an analgesic effect or pain reduction. ${ }^{22}$

\section{Mechanism of Core Stability Exercise to Im- prove Functional Ability}

LBP patients generally experience the fearavoidance model (FAM), a phenomenon in which patients fear performing body movements, daily routines or sports activities because of pain and patients tend to avoid related activities. ${ }^{17}$ However, the FAM could decrease physical activity, increase stiffness in the lower back, which worsens quality of life, permanent functional disability, and sensation of pain. ${ }^{17}$ Core stability exercises might overcome the FAM by reducing the sensation of pain and enhance trunk ROM and neuromuscular control that enhance daily activities of HNP patients. ${ }^{17}$ Moreover, when the core stability exercise uses drawing-in manoeuvres, this would help activate vertebral column stability muscles such as $\mathrm{m}$. transversus abdominis, m. multifidus, which enhancing the endurance in lumbar stability muscles. $^{23}$

\section{CONCLUSION}

This case study concludes that core stability exercises effectively improve pain level and functional ability measured by the VAS and MOLBPDQ parameters on the patient with lumbar HNP.

\section{CONFLICT OF INTEREST}

There is no conflict of interest.

\section{ACKNOWLEDGEMENT}

N/A 


\section{AUTHOR CONTRIBUTIONS}

ADP conceived and designed the study. MES collected the patient information, did the examinations and exercises for the patient. All authors drafted the manuscript, contributed to manuscript revisions.

\section{REFERENCES}

1. Kurniawan R. Profil kesehatan Indonesia tahun 2018: Kementerian Kesehatan RI; 2019.

2. Amin RM, Andrade NS, Neuman BJ. Lumbar Disc Herniation. Curr Rev Musculoskelet Med. 2017;10(4):50716.

3. Dydyk AM, Ngnitewe Massa R, Mesfin FB. Disc Herniation. StatPearls. Treasure Island (FL): StatPearls Publishing Copyright (c) 2021, StatPearls Publishing LLC.; 2021.

4. Meliala L, Pinzon $\mathrm{R}$, editors. Patofisiologi dan Penatalaksanaan Nyeri Pinggang Bawah. Dalam: Meliala L, Rusdi I, Gofir A, editor Pain Symposium: Towards Mechanim Based Treatment, Jogjakarta, hal; 2004.

5. Yusuf A, SYARAT DSSS. Hubungan antara derajat hernia nukleus pulposus (HNP) dengan derajat nyeri punggung bawah di Rumah Sakit Umum Pusat Dr. Wahidin Sudirohusodo Makassar. 2017.

6. Pristianto A, Rahman F. Terapi Latihan Dasar: Muhammadiyah University Press; 2018.

7. Wahyuddin W, Ivanali K, Harun A. Adaptasi Lintas Budaya Modifikasi Kuesioner Disabilitas untuk Nyeri Punggung Bawah (Modified Oswestry Low Back Pain Disability Questionnaire/ODI) Versi Indonesia. Jurnal Ilmiah Fisioterapi. 2016;16(2):5-7.

8. Aithala JP, Kumar S, Aithal S, Kotian SM. Development of a Modified Disability Questionnaire for evaluating disability caused by backache in India and other developing countries. Asian spine journal. 2018;12(6):1106.

9. Parks K, Crichton K, Goldford R, McGill S. A comparison of lumbar range of motion and functional ability scores in patients with low back pain: assessment for range of motion validity. Spine (Phila Pa 1976). 2003;28(4):380-4.

10. Helen J, Dale A, Marybeth B. Techniques of manual examination and performance testing. Tokyo: Kyodo Isho Shuppan; 2014.

11. Silas C, Tobing S. Evaluation of Quality of Life Using Short Form-36 and Visual Analogue Scale After Posterior Instrumentation and Fusin in Tuberculous Spondylitis Patients at Cipto Mangunkusumo Hospital. Journal of Indonesian Orthopaedic. 2012;40(2):21-4.

12. Norton K, Whittingham N, Carter L, Kerr D, Gore C, Marfell-Jones M. Measurement techniques in anthropometry. Anthropometrica. 1996;1:25-75.
13. Paulsen F, Waschke J. Sobotta tables of muscles, joints and nerves, english/Latin: Tables to 16th Ed. of the Sobotta Atlas: Elsevier Health Sciences; 2018.

14. Rodriguez-Beato FY, De Jesus O. Physiology, Deep Tendon Reflexes. StatPearls [Internet]. 2020.

15. Magee DJ. Orthopedic physical assessment. J Hand Ther. 1998;11:286-.

16. Gaowgzeh RAM, Chevidikunnan MF, BinMulayh EA, Khan F. Effect of spinal decompression therapy and core stabilization exercises in management of lumbar disc prolapse: A single blind randomized controlled trial. J Back Musculoskelet Rehabil. 2020;33(2):225-31.

17. Dohnert B, Schwanck Borges C, Evaldt AS, de Jesus Francisco C, da Silva Dias L, Chuaste Flores B, et al. Lumbopelvic Stabilization Exercises and McKenzie Method in Low Back Pain Due to Disc Protrusion: A Blind Randomized Clinical Trial. Muscles, Ligaments \& Tendons Journal (MLTJ). 2020;10(4).

18. Takaki S, Kaneoka K, Okubo Y, Otsuka S, Tatsumura M, SHIINA I, et al. Analysis of muscle activity during active pelvic tilting in sagittal plane. Physical therapy research. 2016;19(1):50-7.

19. Yoon J-O, Kang M-H, Kim J-S, Oh J-S. Effect of modified bridge exercise on trunk muscle activity in healthy adults: a cross sectional study. Brazilian journal of physical therapy. 2018;22(2):161-7.

20. Szczygieł E, Blaut J, Zielonka-Pycka K, Tomaszewski K, Golec J, Czechowska D, et al. The impact of deep muscle training on the quality of posture and breathing. Journal of motor behavior. 2018;50(2):219-27.

21. Kostadinović S, Milovanović N, Jovanović J, TomaševićTodorović S. Efficacy of the lumbar stabilization and thoracic mobilization exercise program on pain intensity and functional disability reduction in chronic low back pain patients with lumbar radiculopathy: A randomized controlled trial. J Back Musculoskelet Rehabil. 2020(Preprint):1-11.

22. Paungmali A, Joseph LH, Punturee K, Sitilertpisan P, Pirunsan U, Uthaikhup S. Immediate effects of core stabilization exercise on $\beta$-endorphin and cortisol levels among patients with chronic nonspecific low back pain: a randomized crossover design. J Manipulative Physiol Ther. 2018;41(3):181-8

23. Bhadauria EA, Gurudut P. Comparative effectiveness of lumbar stabilization, dynamic strengthening, and Pilates on chronic low back pain: randomized clinical trial. Journal of exercise rehabilitation. 2017;13(4):477

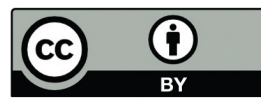

This work is licensed under a Creative Commons Attribution 